pag

Business School

WORKING PAPER SERIES

Working Paper

2014-050

\section{Volatility spillovers and macroeconomic announcements: evidence from crude oil markets}

Aymen Belgacem

Anna Creti

Khaled Guesmi

Amine Lahiani

http://www.ipag.fr/fr/accueil/la-recherche/publications-WP.html

IPAG Business School

184, Boulevard Saint-Germain

75006 Paris

France 


\title{
Volatility spillovers and macroeconomic announcements: evidence from crude oil markets
}

\author{
Aymen Belgacem ${ }^{1}$; Anna Creti $^{2}$; Khaled Guesmi $^{3}$; Amine Lahiani ${ }^{4}$
}

\begin{abstract}
The paper employs an event study methodology to investigate the macroeconomic announcements effects on S\&P500 and oil prices. Our results provide evidence of a significant impact of the US macroeconomic news on oil prices. This impact is split into two components, namely the direct effect (common response) and indirect effect (volatility transmission). Altogether our results show that the volatility transmission is bidirectional since a significant volatility transmission from the oil market to the US stock market is revealed. Furthermore, a higher volatility transmission is recorded from the oil market to the stock market especially after the release of consumption indicators.
\end{abstract}

Keywords: Stock Prices, Oil prices, Macroeconomic Announcements, Volatility Spillovers.

JEL Classification: G14, G15, C58

\footnotetext{
${ }^{1}$ LEO-UMR 7322, University of Orléans

${ }^{2}$ LeDA, Universtié Paris Dauphine, France \& Ecole Polytechnique, France

${ }^{3}$ Department of Finance, IPAG Lab, IPAG Business School, France EconomiX - CNRS (UMR 7235), University of Paris Ouest Nanterre La Défense, France

${ }^{4}$ LEO-UMR 7322, University of Orléans \& ESC Rennes Business School, France
} 


\section{Introduction}

The relationship between commodity markets and macroeconomic fundamentals receives a considerable amount of interest in both the economic press and the academic literature. While some papers test whether oil prices reflect economic fundamentals and thus affect the macroeconomy (Hamilton, 2008; Kilian and Lutz, 2008) or monetary policy rules (Kilian and Vega, 2011; Elder et al, 2012) investigate the impact of macroeconomic news on commodity markets, to select the indicators mostly considered by professionals, especially when valuing oil prices. Understanding the impact of scheduled macroeconomic announcements on commodity markets is indeed of great interest to test the market efficiency hypothesis and anticipate the reaction of domestic as well as foreign investors and policymakers to news arrival.

This paper contributes to the analysis of the relationship between scheduled macroeconomic announcements and oil prices. Previous literature on the impact of macroeconomic announcements has mostly focused on financial markets (e.g. Mcqueen and Roley, 1993; Rigobon and Sack, 2006; Dubreuille and Mai, 2009, Dimpfel, 2011). Moreover, some papers have tested the relationship between US macroeconomic announcements and some foreign markets. This is motivated by the central role of the U.S in determining the development of the world economy For instance Nikkinen and Sahlstrom (2004) find a significant impact of such announcements on foreign financial markets. Dubreuille and Mai (2009) argue that the volatility in the European stock market doubles five minutes following US macroeconomic announcements. So far, few papers to date investigated the impact of macroeconomic news on commodity markets (Barnhart, 1989; Hess et al., 2008; Roache and Rossi, 2010) and specially oil markets (Kilan and Vega, 2011; Chatrath et al., 2011). Almost all of these studies agree that macroeconomic news have little impact on commodity returns and volatility. However, the literature shows mixed results regarding the impact of US announcement on commodity prices. These results are sensitive to data frequency (daily, monthly or quarterly) and business cycle (expansion versus recession). Hess et al. (2010) find that the reaction is state dependant. During recessions, news about higher inflation and real activity lead to positive adjustments of commodity futures prices. In contrast, they find no significant reactions during economic expansions. Elder et al. (2012) use intraday data and find strong evidence of significant jumps around some macroeconomic news. Engle and Rangel (2008) find evidence of a significant relationship between the market volatility and macroeconomic variables such as inflation, growth and macroeconomic volatility.

The event study methodology several advantages over competing methods. First, it allows assessing the impact of the US news immediately after their release and thus the contemporaneous effect of the news on stock prices can be measured. Second, the methodology allows treating the US announcements as exogenous variables and thus the problem of endogeneity is avoided in the regression.

We go beyond this result by disclosing the sources of the reaction to such announcements. In a standard way, and according to the market efficiency hypothesis, an unanticipated U.S. macroeconomic announcement, as any other public information, must be directly incorporated into oil prices (Balduzzi et al, 2001). Another possible explanation is that this reaction is indirect and is due to cross market hedging (Fleming et al., 1998; Belgacem and Lahiani, 2012). Explicitly, macroeconomic announcements, like any other information, may affect the volatility of financial markets, a movement that spreads to commodity markets. 
Several studies have focused on this channel of volatility spillover effect in the context of stock markets (Hsin, 2004 ; Harju and Hussain, 2008), exchange markets (Kanas, 2000; Chen and Gau, 2010 ; Ben Omrane and Heinen, 2011), CDS markets (Galil and Soffer, 2011) options markets (Diavatopoulos et al, 2012) interest rate markets (Monticini et al., 2011), metal futures markets (Elder et al., 2012) and commodity markets (Roache and Rossi, 2010). These studies generally find evidence of return and volatility transmission across major market returns and volatilities and argue that good (bad) news in one market can stabilize (destabilize) other markets (Belgacem and Lahiani, 2012). So far, there is no attempt to test if macroeconomic news causes volatility transmission across markets ${ }^{5}$.). Our paper fills this gap by looking at oil prices and stock markets.

Event studies on the impact of macroeconomic announcements and studies about volatility spillovers in oil markets have been investigated independently. However, combining the two themes gives some more explanations to the issue of the impact of macroeconomic approaches on crude oil markets and particularly allows to answer the following question: do the movements observed in crude oil markets after the release of U.S. economic news represent common responses to such information (direct responses) or a transmission effect from financial market to oil market (indirect response)? This study is the first attempt to answer the latter question.

Using daily data over the period from January 3, 2000 to May 31, 2011, we find evidence of significant responses of oil market to some US macroeconomic announcements. This result is in line with those found in the related literature and confirms that foreign investors regard US macroeconomic news as an important source of information when valuing oil prices. Furthermore, results show evidence of volatility spillovers from the oil market to the US stock market.

The remaining of the paper is organized as follows. In section 2 we introduce the model. Section 3 presents the data and preliminary results. Section 4 discusses the main findings of the paper. Section 5 concludes.

\section{Methodology}

As shown in the introduction above, there is no consensus about the transmission effect from financial markets to the crude oil market. We thus propose to revisit this question and study the interactions between the US stock market and the crude oil market. The existence of volatility spillovers between the two markets may confirm our hypothesis of a transmission effect from financial to the crude oil market after the release of macroeconomic announcements.

In order to highlight the spillover effect between financial and energy markets, multivariate GARCH-type models have mostly been used in the literature on volatility transmission as they allow for the joint modeling of variances and covariances between different variables. Among the different specifications of the multivariate GARCH models, (i.e CCC, DCC,

\footnotetext{
${ }^{5}$ Belgacem and Lahiani (2012) argue that this distinction between good and bad news is in some cases criticized. In some circumstances, the same information may be considered as good or bad news, depending on investors' perception of it, making unclear the distinction between the two categories of news. It becomes therefore crucial to analyze volatility transmission by considering the nature and the type of the announcement, rather than its sign.
} 
VECH and BEKK ${ }^{6}$ ), we propose to use the DCC-GARCH of Engle (2002). This choice is motivated by the following three reasons (Belgacem and Lahiani, 2012): first, the superiority of the DCC-GARCH model over the other multivariate GARCH specifications when studying financial markets dynamics is largely documented in the literature, as it takes into account dynamic correlation between financial and economic data. Second, the conditional correlation between equity markets is shown to time-varying (see also Longin and Solnik, 1995). Finally, compared to the other multivariate GARCH specifications, the DCC-GARCH presents the advantage of having less parameters to estimate, which allows us to augment the model by introducing a set of macroeconomic variables and testing for the direct/indirect effects of US macroeconomic news without burdening the estimation procedure.

Consider the vector of returns in two markets $R_{t} \equiv\left[R_{t}^{E}, R_{t}^{S P}\right]^{\prime}$, with $R_{t}^{E}$ and $R_{t}^{S P}$ being the returns on energy market and the US stock market at time $t$, respectively. The conditional mean equation can be written as follows:

$$
R_{t}=\alpha+\sum_{i=1}^{n} \beta_{i} R_{t-i}+\varepsilon_{t}
$$

Where

- $\varepsilon_{t} \equiv\left[\varepsilon_{t}^{E}, \varepsilon_{t}^{S P}\right]^{\prime}$ with $\varepsilon_{t}^{E}$ and $\varepsilon_{t}^{S P}$ being error terms from the mean equations of energy and the US stock markets respectively.

- $H_{t} \equiv D_{t} C_{t} D_{t}$ is the variance-covariance matrix

- $D_{t}=\operatorname{diag}\left\{\sqrt{h_{E, t}}, \sqrt{h_{S P, t}}\right\}$ is the diagonal matrix of time varying standard deviations, which can be estimated using a GARCH (p, q) model.

- $C_{t}=\left\{\rho_{E / S P, t}\right\}$ represents the conditional correlation matrix between energy market and stock market. The dynamic conditional correlation (DCC) process of orders $\mathrm{M}$ and $\mathrm{N}$ has the following representation:

$$
\begin{gathered}
C_{t}=\left(Q_{t}^{*}\right)^{-1} Q_{t}\left(Q_{t}^{*}\right)^{-1} \\
Q_{t}=\left(1-\sum_{m=1}^{M} a_{m}-\sum_{n=1}^{N} b_{n}\right) \bar{Q}+\sum_{m=1}^{M} a_{m}\left(\xi_{t-m} \xi_{t-m}^{\prime}\right)+\sum_{n=1}^{N} b_{n} Q_{t-n}
\end{gathered}
$$

where $\xi_{t}$ is the vector of the standardized residuals extracted from the estimation of the univariate GARCH, $Q_{t}$ is the variance-covariance matrix of these conditional standardized residuals, $\bar{Q}=E\left(\xi_{t} \xi_{t}^{\prime}\right)$ represents the unconditional variance-covariance matrix, and finally $Q_{t}^{*}$ is the diagonal matrix containing the square root of the diagonal elements of $Q_{t}$. For a pair of markets $i$ and $j$, the conditional correlation at time $t$ can be written as:

$$
\rho_{i j, t}=\frac{\left(1-\theta_{1}-\theta_{2}\right) \bar{q}_{i j}+\theta_{1} u_{i, t-1} u_{j, t-1}+\theta_{2} q_{i j, t-1}}{\left[\left(1-\theta_{1}-\theta_{2}\right) \bar{q}_{i i}+\theta_{1} u_{i, t-1}^{2}+\theta_{2} q_{i i, t-1}\right]^{\frac{1}{2}}\left[\left(1-\theta_{1}-\theta_{2}\right) \bar{q}_{j j}++\theta_{1} u_{j, t-1}^{2}+\theta_{2} q_{j j, t-1}\right]^{\frac{1}{2}}}
$$

where $q_{i j}$ is the element on the $i^{\text {th }}$ line and $i^{\text {th }}$ column of the matrix $Q_{t}$.

\footnotetext{
${ }^{6}$ CCC: Constant Conditional Correlation of Bollerslev, 1990; DCC: Dynamic Conditional Correlation of Engle, 2002; VECH: Multivariate GARCH with time varying covariances of Bollerslev, Engle and Wooldridge, 1988; BEKK: Multivariate GARCH of Baba, Engle, Kraft and Kroner, 1991;
} 
The parameters are estimated using Quasi-Maximum Likelihood Estimation (QMLE) introduced by Bollerslev and Wooldridge (1992). So, for each variable, we can obtain the conditional variance and the conditional covariance. Under the Gaussian assumption, the likelihood function can be rewritten as:

$L(\theta)=-\frac{1}{2} \sum_{t=1}^{T}\left(n \log (2 \pi)+2 \log \left|D_{t}\right|+\log \left|R_{t}\right|+u_{t}^{\prime} R_{t}^{-1} u_{t}\right.$

with $u_{t}=\frac{\varepsilon_{t}}{\sqrt{h_{t}}}=D_{t}^{-1} \varepsilon_{t} u_{t}$

In order to take into account the spillovers between stock and oil markets, we augment the basic model (Eq. 1) so that it allows detecting not only the direct reaction of the energy market to the release of US macroeconomic announcements, but also the transmission (indirect) effects from US stock market to the oil market. To do so, we consider two augmented DCC-GARCH models. The first one is modified by adding the variance of the stock market in the variance equation of the oil market and vice versa. We can therefore test volatility transmission between the two markets. Formally, the regression is as follows:

$h_{E, t}=\omega_{E}+\alpha_{E} \varepsilon_{E, t-1}^{2}+\beta_{E} h_{E, t-1}+\theta_{E} h_{S P, t-1}$
$h_{S P, t}=\omega_{S P}+\alpha_{S P} \varepsilon_{S P, t-1}^{2}+\beta_{S P} h_{S P, t-1}+\theta_{S P} h_{E, t-1}$

Afterwards, we augment the basic model by jointly adding the variance of the US market in the variance equation of the energy market and vice versa as well as the US macroeconomic shocks simultaneously in the two volatility equations. The model has the following specification:

$h_{E, t}=\omega_{E}+\alpha_{E} \varepsilon_{E, t-1}^{2}+\beta_{E} h_{E, t-1}+\sum_{k=1}^{11} \delta_{E, k} S_{k, t}+\sum_{k=1}^{11} \theta_{E, k} D_{k} h_{S P, t-1}$
$h_{S P, t}=\omega_{S P}+\alpha_{S P} \varepsilon_{S P, t-1}^{2}+\beta_{S P} h_{S P, t-1}+\sum_{k=1}^{11} \delta_{S P, k} S_{k, t}+\sum_{k=1}^{11} \theta_{S P, k} D_{k} h_{E, t-1}$

$S_{t}$ is the standardized surprise ${ }^{7}$ of the $k^{\text {th }}$ US macroeconomic announcement, $D_{k}$ is a dummy variable taking the value 1 on the days of $\mathrm{k}^{\text {th }}$ news announcements, and 0 otherwise. The term $\sum_{k=1}^{11} \theta_{E, k} D_{k} h_{S P, t-1}$ in eq. (8) and (9) allows detecting the volatility spillover from US market to oil market after the release of US macroeconomic indicators, while the term $\sum_{k=1}^{11} \emptyset_{E, k} S_{k, t}$ captures the direct effect of the US announcements on the volatility of oil market.

\section{Data and descriptive statistics}

\footnotetext{
${ }^{7}$ A surprise is the unexpected component of the macroeconomic announcement and calculated as the difference between the real change and the market expected change. This issue will be explained with more details in Section 3.
} 
We collect prices of the S\&P500 and WTI from Datastream over the period from February $3^{\text {rd }}, 2000$ to May $31^{\text {st }}, 2011$. We should notice that the WTI price is used in this paper rather than BRENT as a proxy of oil market in order to handle out the problem of nonsynchronous trading, which arises due to the difference between trading hours across countries when using daily data (Belgacem and Lahiani, 2012; Martens and Poon, 2001; Soriano and Climent, 2005).

Descriptive statistics of the S\&P500 and WTI returns are summarized in Panel A and B of Table 1 in the Appendix. The average daily returns are low and negative for the US market under the effect of the global financial crisis and positive and close to zero for the WTI market. Skewness is negative for the WTI series and positive for SP500 indicating that extreme negative and positive returns are likely to be present in the two market return series. Kurtosis values are high meaning that outliers may occur with a higher probability than that of a normal distribution. Moreover, we carried out the LM ARCH test of Engle (1982). Results show that the null hypothesis of no ARCH effect, are rejected at the $1 \%$ significance level for the two return series. This confirms that a GARCH modelling is adequate to capture the heteroskedasticity in the volatilities series. Panel $\mathrm{C}$ reveals a positive and significant unconditional correlation coefficient across the two considered markets suggesting that these markets are relatively dependent on each others. All of these preliminary results confirm that the VAR-GARCH used hereafter is adequate to describe the dynamics of the two markets around macroeconomic announcements.

Regarding macroeconomic announcements, the data sample consists of the following U.S. news which have been shown to significantly affect equity prices in recent papers: ${ }^{8}$

- Consumer and producer price indices (monthly) as indicators of inflation;

- Unemployment rate (monthly) considered as one of the most timely indicators of the economic state;

- Industrial production (monthly), the gross domestic production (quarterly), the leading indicator that predicts change in the economy as a whole, the ISM index that allows understanding national economic conditions and the trade balance to proxy the state of the economic activity;

- Consumer confidence index (monthly) and household consumption (monthly);

- Housing starts (monthly) as a real estate indicator.

We use American economic announcements to investigate their effect on oil and stock markets respectively. Announcement dates of macroeconomic indicators are collected from both BLS (Bureau of Labor Statistics) web site and checked afterwards through Bloomberg. We also try to separate the expected from the unexpected components of the news. The standard way to do this is to compute the surprise as the difference between the real change of the indicator value from the market consensus forecast. One way of making surprises comparable is to divide them by their standard deviation, as described in Fleming and Remolona (1997) and Balduzzi et al. (2001). Bloomberg and MMS9 forecasts are used to measure the market median consensus forecasts of macroeconomic news. Descriptive statistics of the latter are presented in panel B in the appendix 1 and show that most of the news are characterized by negative average returns due to the global financial crisis.

\footnotetext{
${ }^{8}$ See e.g. Jones et al. (2005), Rigobon and sack (2006) and Dubreuille (2007). The data is also chosen according to its availability in Money Market Services Database.

${ }^{9}$ MMS : Money Market Services Database
} 


\section{Volatility spillovers between oil and stock markets}

Estimation results of the first augmented model c.f Eqs (6) and (7) are reported in Table 2. Firstly, it should be noted that the coefficients $a_{1}$ and $b_{1}$ of the DCC equation are highly significant, which confirm the adequate specification of the model and the existence of a time varying correlation between the two series.

\section{$<$ Insert Table 2 here $>$}

As for the volatility transmission, our results show strong volatility spillovers across these markets, with a neat transmission from the US stock market to the oil market. The table also shows that a positive (negative) shock causes an increase (decrease) of volatility in the US market which, in turn, leads to a rise (fall) of volatility of the WTI. A similar effect is also observed from the oil market to the stock market: an increase of $0.2 \%$ of the volatility in the U.S. market is explained by a rise of volatility of the WTI. Our results are in line with the conclusions of Sadorsky (1999), Chiou and Lee (2009), Hammoudeh (2010) who argue for the existence of a volatility spillover from the US market to oil prices.

\section{Volatility spillovers and macroeconomic announcements}

Do the movements observed in the two markets after the release of U.S. macroeconomic surprises represent a common response to such information or a transmission effect from U.S. market, or even both? One way to empirically answer the question is to use the augmented DCC-GARCH model as described by Eqs. (8) and (9). Results are reported in Table (3).

$$
<\text { Insert Table } 3 \text { here }>
$$

Regarding the direct effect of US macroeconomic news on the oil market news, we note that the volatility of the WTI stock index increases significantly following a positive surprise in the U.S. unemployment rate and housing starts announcements. The opposite effect is observed following a positive surprise increase in industrial production and GDP index, with a stronger sensitivity to the latter type of news. This result confirms the hypothesis that oil prices are in some proportion driven by macroeconomics.

Table 3 also reports significant volatility spillovers from the US stock market to the oil market after the announcement of the US unemployment, consumer price index, household consumption, GDP, housing market increase, consumer confidence index and the leading indicator. Indeed, an increase in the previous three indicators leads to an increase in the volatility of the US stock market, which in turn impacts positively the volatility of the oil market.

In addition, Table (3) shows a significant spillover effect from the oil market to the US stock market after the release of information on the US household consumption, consumer confidence and ISM indicator. An increase in the WTI's volatility leads to an increase in the S\&P500's volatility, with the highest effect for the ISM index and the lowest effect for consumer confidence. These results confirm the hypothesis that some of the US macroeconomic announcements are able to generate volatility transmission from the US stock market to the oil market and vice versa.

All in all, our results show evidence of a significant impact of the US macroeconomic surprises on oil markets. This impact is split into two types namely the direct effect (common response) and indirect effect (volatility transmission). Moreover, our results show that the volatility transmission is bidirectional since a significant volatility transmission from the oil market to the US stock market is revealed. Furthermore, an important volatility transmission 
is recorded from the oil market to the stock market, especially after the release of consumption indicators.

The previous results - mainly those concerning the bidirectional volatility spillover between the two markets - show that interactions are bidirectional and therefore they highlight an important integration between the US stock market and oil market. These findings are in line with those of Hammoudeh et al. (2004) on the two-way interactions between the S\&P Oil Composite index, and oil spot and futures prices, as well as with Chiou and Lee (2009) on the asymmetric unexpected effects of oil prices on stock returns, and finally with Malik and Ewing (2009) regarding spillover mechanisms between weekly WTI oil prices and equity sector returns.

\section{Conclusion}

This paper investigates the effects of US macroeconomic surprises on US stock market index and oil prices volatilities using an augmented multivariate GARCH framework. We introduce a multivariate GARCH model that accounts for cross effects of volatilities in the two markets which allows measuring the volatility transmission.

Our setting provides interesting insights into the dynamics of international equity markets. This paper mainly contributes to the existing literature by separating the direct effect from indirect effect of US macroeconomic news on US stock market and oil prices. Thus, this paper presents evidence of common reactions of international investors to US macroeconomic announcements. The latter reactions represent the direct effects of US macroeconomic surprises on the US stock market and oil prices. The paper also allows to explain the causes of volatility transmission between the US market and oil prices by selecting the most significant news that drive this volatility spillover as well as the direction of the transmission. The volatility transmission is considered as the indirect effect of US macroeconomic news on oil prices in our setting.

These results have important implications for market participants and portfolio managers as US macroeconomic announcements have direct and indirect impacts on asset prices and oil prices. Investors in the US stock market as well as those in the Oil market should be able to measure the direct and immediate impact of the US releases and also aware of the risk coming from the transmission of volatility from the other market. Availing their selves of the investment opportunities that occur shortly after the macroeconomic announcement in the US and hedging against the risk of contagion are of great importance for the actors in the stock and oil markets. 


\section{Appendix}

Table 1: Descriptive statistics

Panel A: Market returns descriptive statistics

\begin{tabular}{lll} 
& WTI & S\&P 500 \\
\hline Mean & 4.4 E-4 & $-3.41 \mathrm{E}-5$ \\
\hline Std deviation & 0.026 & 0.013 \\
\hline Skewness & -0.162 & 0.013 \\
\hline Kurtosis & 8.114 & 10.829 \\
\hline Jarque-Bera & 3228.65 & 7541.35 \\
\hline p-value & {$[0.000]$} & {$[0.000]$} \\
\hline ARCH(10) & 32.987 & 48.560 \\
\hline p-value & {$[0.000]$} & {$[0.000]$} \\
\hline ARCH(20) & 43.763 & 67.24 \\
\hline p-value & {$[0.001]$} & {$[0.000]$} \\
\hline Q(10) & 15.171 & 13.253 \\
\hline p-value & {$[0.126]$} & {$[0.209]$} \\
\hline
\end{tabular}

Panel B: Unconditional Correlations across stock markets

\begin{tabular}{ccc} 
& WTI & S\&P500 \\
\hline WTI & 1 & 0.164 \\
& & {$[0.000]$} \\
\hline SP500 & & 1 \\
\hline
\end{tabular}

p-values are between brackets

\section{Panel C:}

Descriptive statistics of (non standardized) macroeconomic surprises

\begin{tabular}{lccccccccccc}
\hline & CPI & PPI & HCON & UNEM & GDP & IP & CONF & HS & LI & ISM & TB \\
\hline Observations & 136 & 136 & 136 & $136(\mathrm{M})$ & 47 & 136 & 136 & 136 & 136 & 136 & 136 \\
\hline Mean & -0.005 & 0.035 & -0.006 & -0.012 & -0.16 & -0.084 & -0.03 & 8.992 & -0.004 & 0.089 & 0.016 \\
\hline Std Error & 0.18 & 0.523 & 0.201 & 0.158 & 0.874 & 0.467 & 5.26 & 89.477 & 0.224 & 2.111 & 3.231 \\
\hline Maximum & 0,4 & 1.6 & 0.6 & 0.5 & 0.8 & 1.5 & 12.8 & 275 & 0.6 & 7.4 & 11.1 \\
\hline Minimum & $-0,6$ & -1.3 & -0.8 & -0.5 & -5.6 & -3.3 & -13 & -253 & -0.5 & -6.1 & -9.1
\end{tabular}

Notes: (M): Monthly, (Q): Quarterly, CPI: Consumer price index, PPI: Producer price index, HCON: Household consumption, UNEM: Unemployment rate, GDP: Gross domestic production, IP: Industrial production, CONF: Consumer confidence, HS: Housing starts, LI: Leading indicator, ISM: ISM manufacturing, TB: Trade Balance 
Table 2: Estimation of the augmented model in Eqs (5) and (6)

\begin{tabular}{lllll}
\hline & \multicolumn{2}{c}{ S\&P500 } & WTI \\
\cline { 2 - 4 } Mean Equation & Coefficient & t-value & Coefficient & t-value \\
Constant & $\mathbf{4 . 1 7 E - 4}$ & 2.48 & $\mathbf{9 . 8 7}$ E-4 & 2.519 \\
S\&P (1) & $\mathbf{- 0 . 0 6 6}$ & -3.21 & $\mathbf{0 . 0 9 5}$ & 2.809 \\
WTI(1) & -4.05 E-3 & -0.531 & $\mathbf{- 0 . 0 3 7}$ & -2.069 \\
\hline Variance Equation & & & & \\
Constant & 5.64 E-7 & 1.261 & $\mathbf{1 . 8 6}$ E-5 & 5.37 \\
$\varepsilon_{t-1}^{S P}$ & $\mathbf{0 . 0 7 7}$ & 10.532 & ------ & ------ \\
$\varepsilon_{t-1}^{W T I}$ & ------ & ------- & $\mathbf{0 . 0 6 8}$ & 10.057 \\
$h_{t-1}^{S P}$ & $\mathbf{0 . 9 1 2}$ & 113.69 & $\mathbf{0 . 0 3 8}$ & 2.332 \\
$h_{t-1}^{W T I}$ & $\mathbf{1 . 8 4} \mathbf{E - 3}$ & 1.978 & $\mathbf{0 . 8 9 2}$ & 72.445 \\
\hline
\end{tabular}

\section{$\underline{\text { DCC Equation }}$}

$\begin{array}{ll}a_{1} & \mathbf{0 . 0 2 4}(\mathbf{8 . 5 3 )} \\ b_{1} & \mathbf{0 . 9 7 3 ( 3 0 4 . 3 2 )} \\ \underline{\text { Log-Likelihood }} & 15848.36 \\ \underline{\text { Q(12) }} & 47.6[0.48]\end{array}$

Note: $t$-statistics are between parentheses, $\mathrm{p}$-values are between brackets 
Table 3: Estimation of the augmented model Eqs (7) and (8)

\begin{tabular}{|c|c|c|c|c|}
\hline Variables & S\&P500 & $t$-value & WTI & $t$-value \\
\hline \multicolumn{5}{|l|}{ Mean Equation } \\
\hline Constant & 0.36 E-3 & 2.001 & 0.84 E-3 & 2.318 \\
\hline $\mathrm{CAC}(1)$ & -0.057 & -2.632 & 0.093 & 2.633 \\
\hline $\mathrm{SP}(1)$ & -0.007 & -0.928 & -0.029 & -1.567 \\
\hline \multicolumn{5}{|l|}{ Variance Equation } \\
\hline Constant & 0.75 E-6 & 1.507 & 0.183 E-4 & 3.924 \\
\hline$\varepsilon_{t-1}^{2}$ & 0.079 & 10.013 & 0.055 & 5.866 \\
\hline$h_{t-1}$ & 0.91 & 106.86 & 0.899 & 50.518 \\
\hline \multicolumn{5}{|l|}{ Direct Effects } \\
\hline Unemployment & 6.918 E-06 & 1.742 & 5.178 E-05 & 2.5 \\
\hline CPI & 4.257 E-06 & 1.037 & -2.357 E-05 & -0.715 \\
\hline Household Cons & -2.868 E-06 & -0.751 & $1.677 \mathrm{E}-05$ & 0.729 \\
\hline Industrial Prod & -4.59 E-06 & -0.979 & -7.273 E-05 & -2.162 \\
\hline Housing Starts & -6.136 E-06 & -1.898 & 7.586 E-05 & 2.635 \\
\hline GDP & 2.847 E-05 & 2.188 & $-2.2 \mathrm{E}-04$ & -2.32 \\
\hline Consumer Confidence & 2.952 E-06 & 0.583 & 3.844 E-05 & 1.316 \\
\hline ISM Index & 4.283 E-06 & 1.133 & 4.139 E-06 & 0.158 \\
\hline PPI & 6.394 E-06 & 2.409 & -3.158 E-05 & -1.11 \\
\hline Leading Indicators & -2.388 E-06 & -0.7 & 7.232 E-06 & 0.268 \\
\hline Trade Balance & -3.556 E-06 & -1.138 & -1.731 E-06 & -0.052 \\
\hline \multicolumn{5}{|l|}{ Indirect Effects } \\
\hline Unemployment & -0.006 & -0.553 & -0.607 & -3.566 \\
\hline CPI & -0.018 & -1.363 & -0.935 & -1.777 \\
\hline Household Cons & -0.047 & -6.578 & -0.652 & -2.315 \\
\hline Industrial Prod & 0.023 & 1.249 & 0.261 & 0.51 \\
\hline Housing Starts & 0.023 & 1.135 & 0.604 & 1.651 \\
\hline GDP & 0.018 & 1.442 & -0.932 & -3.794 \\
\hline Consumer Confidence & 0.027 & 2.311 & 1.208 & 3.473 \\
\hline ISM Index & 0.049 & 3.479 & 0.436 & 1.583 \\
\hline PPI & 0.008 & 0.655 & 0.161 & 0.773 \\
\hline Leading Indicator & -0.015 & -1.003 & 0.839 & 2.502 \\
\hline Trade Balance & -0.013 & -1.232 & 0.342 & 1.203 \\
\hline \multicolumn{5}{|l|}{ DCC Equation } \\
\hline$a_{1}$ & \multicolumn{4}{|l|}{$0.025(3.467)$} \\
\hline$b_{1}$ & \multicolumn{4}{|l|}{0.972 (118.87) } \\
\hline$\underline{\text { Log-Likelihood }}$ & \multicolumn{4}{|l|}{15916.49} \\
\hline$Q(12)$ & \multicolumn{4}{|l|}{$49.37(0.41)$} \\
\hline
\end{tabular}




\section{References}

Baba, Y.; R. F. Engle, D. F. Kraft and K. F. Kroner (1990) "Multivariate simultaneous generalized ARCH.” Mimeo, University of California at San Diego.

Balduzzi, P., Elton, E.J. and T.C. Green (2001) "Economic news and bond prices: Evidence from the U.S. treasury market” Journal of Financial and Quantitative Analysis 36, 523543.

Belgacem, A. and Lahiani, A., (2012). More on the Impact of US Macroeconomic Announcements: Evidence from French and German Stock Markets' Volatility. Economics Bulletin, 32, pp. 1509-1526.

Ben Omrane, W. and A. Heinen (2010) "Public news announcements and quoting activity in the Euro/Dollar foreign exchange market” Computational Statistics and Data Analysis 54, 2419-2431.

Bollerslev T. (1990) "Modeling the coherence in short-run nominal exchange rates: a multivariate generalized ARCH model.” Review of Economics and Statistics 72, 498505.

Bollerslev, T.; R. F. Engle and J. M. Wooldridge (1988): “A capital asset pricing model with time-varying covariances.” The Journal of Political Economy, 96 (1), 116-131.

Bollerslev, T., R. F. Engle and J. M. Wooldridge, A capital asset pricing model with timevarying covariances, Journal of Political Economy, 96 (1988), 116-131.

Chatrah, A.S., Ramchander, S. and F. Song (1995) “Are market perceptions of corporate layoffs changing?” Economics Letters 47, 335-342.

Chen, Y.L. and Y.F. Gau (2010) "News announcements and price discovery in foreign exchange spot and futures markets” Journal of Banking and Finance 34, 1628-1636.

Chiou, J.S., Lee, Y.H. (2009), Jump dynamics and volatility: Oil and the stock markets, Energy 34(6), 788-796.

Diavatopoulos, D., Doran, J.S., Fodor, A. and D.R. Peterson (2012) “The information content of implied skewness and kurtosis changes prior to earnings announcements for stock and option returns” Journal of Banking and Finance 36, 786-802.

Dimpfel, T. (2011) "The impact of US news on the German stock market-An event study analysis” Quarterly Review of Economics and Finance 51, 389-398.

Dubreuille, S. and H.M. Mai (2009) "Impact of European and American Business Cycle News on Euronext Trading” International Journal of Business 14, 124- 135. 
Elder, J., Miao, H. and S. Ramchander (2012) "Impact of macroeconomic news on metal futures” Journal of Banking and Finance 36, 51-65.

Elder, J., Miao, H. and S. Ramchander (2012) “Jumps in Oil Prices: The Role of Economic News”, Working paper.

Engle, R. (1982) “Autoregressive conditional heteroscedasticity with estimates of the variance of United Kingdom inflation” Econometrica 50, 987-1007.

Engle, R. (2002), "Dynamic conditional correlation: A simple class of multivariate generalized autoregressive conditional Heteroskedasticity Models”, Journal of Business \& Economic Statistics 20, 339-350.

Engle, R.F. and J.G. Rangel (2008) “The spline-GARCH model for low-frequency volatility and its global macroeconomic causes” Review of Financial Studies 21, 1187-1222.

Fleming, M.J. and E.M. Remonola (1997) “What moves the bond market?” Economic policy review 3, 31-50.

Fleming, J., Kirby, C. and B. Ostdiek (1998) “Information and volatility linkages in the stock, bond and money markets Journal of financial economics 49, 111-137.

Galil, K. and G. Soffer (2011) "Good News, bad news and rating announcements: an empirical investigation” Journal of Banking and Finance 35, 3101-3119.

Hammoudeh, S., Dibooglu, S. \& Aleisa, E. (2004), Relationships among U.S. oil prices and oil industry equity indices, International Review of Economics and Finance 13(4), 427453.

Hamilton, J. 2008. Understanding Crude Oil Prices. Working Paper 14492. National Bureau of Economic Research.

Harju, K. and S.M. Hussain (2008) Intraday Return and Volatility Spillovers Across International Equity Markets” International Research Journal of Finance and Economics 22, 205-220.

Hess, Dieter E.; Huang, He; Niessen-Ruenzi, Alexandra (2008) : How do commodity futures respond to macroeconomic news?, CFR working paper, No. 08-03

Hsin, C.W. (2004) “A multilateral approach to examining the comovements among major world equity markets” International review of financial analysis 13, 433-462.

Jones, B., Lin, C.T., Mansur, A. and M. Masih (2005) "Macroeconomic announcements, volatility, and interrelationships: an examination of the UK interest rate and equity markets” International Review of Financial Analysis 14, 356-375.

Kanas, A. (2000) "Volatility spillovers between stock returns and exchange rate changes: international evidence” Journal of business and accounting 27, 447-467. 
Kilian, L., (2008) “A Comparison of the Effects of Exogenous Oil Supply Shocks on Output and Inflation in the G7 Countries.” Journal of the European Economic Association, 6(1): 78-121.

Kilian, L., and C. Vega (2011), “Do Energy Prices Respond to U.S. Macroeconomic News? A Test of the Hypothesis of Predetermined Energy Prices,” Review of Economics and Statistics, 93, 660-671.

Malik, F. \& Ewing, B.T. (2009), Volatility transmission between oil prices and equity sector returns, International Review of Financial Analysis, 18, 95-100.

McQueen, G. and V.V. Roley (1993) “Stock prices, news and business conditions” The Review of Financial Studies 6, 683-707.

Monticini, A., Peel. D. and G. Vaciago (2011) The impact of ECB and FED announcements on the Euro interest rates” Economics Letters 113, 139-142.

Nikkinen, J. and P. Sahlstöm (2004) "Scheduled domestic and US macroeconomic news and stock valuation in Europe” Journal of multinational financial management 14, 201-215.

Rigobon, R. and B. Sack (2006) "Noisy Macroeconomic Announcements, Monetary Policy, and Asset Prices” NBER working paper number 12420

Roache, S.K. and M. Rossi (2010) “The effects of economic news on commodity prices” The Quarterly Review of Economics and Finance 50, 377-385.

Sadorsky, P. (1999), Oil price shocks and stock market activity, Energy Economics 21, 449469. 